\title{
Bioprospecção de bactérias com potencial tecnológico para biorremediação de ecossistemas impactados por mercúrio e cromo
}

\section{Adriana Sotero-Martins ${ }^{1,2 *}$ Mônica de OliveiraViana ${ }^{1}$ Elvira Carvajal'}

${ }^{1}$ Programa de Pós-Graduação em Saúde Pública, Departamento de Saneamento e Saúde Ambiental, Escola Nacional de Saúde Pública, Fundação Oswaldo Cruz - Rio de Janeiro (RJ), Brasil.

${ }^{2}$ Departamento de Biologia Celular, Instituto de Biologia Roberto Alcântara, Universidade Estadual do Rio de Janeiro Rio de Janeiro (RJ), Brasil.

*Autor correspondente: adrianasotero@ ensp.fiocruz.br

\section{Resumo}

A bioprospecção de micro-organismos que possam ser utilizados na biorremediação de ecossistemas degradados é o primeiro passo nas pesquisas que visam utilizar a atividade microbiana para converter substâncias tóxicas em compostos menos nocivos. A Baía de Guanabara, no Sudeste do Brasil, constitui um bioma com grande quantidade e diversidade de poluentes lançados em suas águas, o que compromete a saúde ambiental de tal ecossistema. O presente estudo teve como objetivo avaliar o potencial de biorremediação de bactérias isoladas das praias da Baía de Guanabara. Os micro-organismos foram isolados, identificados, guardados em coleção de cultura e investigados em pesquisas biotecnológicas de biorremediação, quanto à resistência aos metais mercúrio e cromo. Foi avaliada a presença de genes envolvidos nos processos de biorremediação, sendo eles os genes merA, ChrA e ChrB. Dos 169 micro-organismos testados, 8,8\% apresentaram resistência ao mercúrio de até $3 \mathrm{mg} / \mathrm{L} \mathrm{e}$, em dois isolados, detectou-se a presença do gene merA. Um total de $25,2 \%$ dos micro-organismos apresentou resistência ao cromo de até $1 \mu \mathrm{g} / \mathrm{L}$. Contudo, em nenhum isolado houve presença dos genes $C h r A$ e $C h r B$ nas condições utilizadas. Palavras-chave: mercúrio, cromo, bactéria, remediação, Baía de Guanabara.

\section{Abstract}

Bioprospecting for microorganisms that may be used in bioremediation of degraded ecosystems is the first step in research aimed at using microbial activity to convert toxic substances into less harmful compounds. The Guanabara Bay, in the Southeast of Brazil, is an extremely productive biome, despite the large number and diversity of pollutants released into its waters, compromising the environmental health of such ecosystem. This study aimed at evaluating the potential for bioremediation of bacteria isolated from the beaches of Guanabara Bay. The microorganisms were isolated, identified, stored in a culture collection, and investigated in biotechnology researches of bioremediation, for resistance to mercury and chromium metals. We assessed the presence of genes involved in bioremediation processes, which were the genes merA, ChrA, and ChrB. Of 169 tested microorganisms, $8.8 \%$ were resistant to mercury up to $3 \mathrm{mg} / \mathrm{L}$ and, in two isolates, the presence of the gene merA was found. A total of $25.2 \%$ of the microorganisms presented resistance to chromium up to $1 \mu \mathrm{g} / \mathrm{L}$. However, it was not found the presence of genes ChrA and ChrB in the used conditions.

Keywords: mercury, chrome, bacteria, remediation, Guanabara Bay. 


\section{INTRODUÇÃO}

A poluição ambiental tem sido um dos grandes problemas da sociedade, estando associada ao alto desenvolvimento industrial. Os resíduos industriais, muitas vezes, não possuem destino apropriado e acabam contaminando a superfície das águas, dos sedimentos e dos solos do meio ambiente (Hutchinson \& Symington 1997; Pereira 2004). O ecossistema da Baía de Guanabara, no Rio de Janeiro, Sudeste do Brasil, apesar da grande quantidade e diversidade de poluentes lançados diariamente em suas águas, ainda é considerado bastante relevante e fundamental para a manutenção da flora e fauna no litoral fluminense do Rio de Janeiro. Parte dos poluentes encontrados nele é de origem industrial e, dentre os resíduos industriais de grande impacto ambiental, estão os metais mercúrio e cromo (Lima \& Legey 2010).

O metal mercúrio é reconhecido como um poluente global por várias agências de proteção ambiental, sendo considerado um elemento muito tóxico por permanecer na cadeia trófica durante um bom período, sendo amplificado em cada nível por bioaumentação (Deng et al. 2006; Hines et al.2006). Cromo, em sua forma tetravalente (IV), também é um contaminante ambiental, possuindo várias aplicações industriais, porém escassas práticas ambientais na disposição de seus resíduos industriais. Alta solubilidade e conformação tetravalente do ânion de cromo permitem seu transporte rápido pelas membranas biológicas e sua internalização pela célula. O Cr (VI) possui uma variedade de efeitos tóxicos,

\section{MATERIAL E MÉTODOS}

Foram isoladas bactérias a partir da água e da areia de praias da Baía de Guanabara. Os locais foram escolhidos de modo a representarem os diferentes microambientes impactados do ecossistema da Baía de Guanabara. Todo material de coleta foi previamente descontaminado em autoclave $\left(121{ }^{\circ} \mathrm{C} / 1 \mathrm{~atm}\right)$ ou por exposição contínua à radiação ultravioleta, em capela de fluxo laminar, durante 40 minutos. As amostras de água e areia foram coletadas em pontos georreferenciados e acondicionadas em recipiente plástico estéril, com capacidade de $50 \mathrm{~mL}$. A massa média em grama de areia seca foi de $53 \mathrm{~g}( \pm 2,1)$ e a de areia úmida foi de $75 \mathrm{~g}( \pm 1,7)$. O material coletado foi processado em até 24 horas, e aquele de areia foi transferido para frascos previamente pesados, com capacidade de $500 \mathrm{~mL}$, seguido da determinação da massa de areia. A água não passou por tal diluição inicial.

Toda massa de areia úmida e seca foi ressuspensa em $200 \mathrm{~mL}$ de solução de água fosfatada e agitada três vezes, em intervalos de 10 minutos (diluição inicial). Em seguida, foram realizadas diluições seriadas para areia úmida, alíquotas de $10 \mathrm{~mL}$ da suspensão inicial de areia úmida foram transferidas para $90 \mathrm{~mL}$ de água fosfatada (primeira diluição em série). Transferiu-se alíquota de $10 \mathrm{~mL}$ da primeira diluição em série para $90 \mathrm{~mL}$ de água fosfatada (segunda diluição em série). Para areia seca, a diluição em série inicial foi feita da mesma forma que em areia úmida, mutagênicos e carcinogênicos. A formação de danos no DNA é a maior causa de respostas tóxicas e mutagênicas no corpo humano e em células bacterianas (Baruthio 1992; Cervantes 2001).

Apesar dos metais pesados serem altamente tóxicos para a maioria dos micro-organismos, há bactérias que são resistentes a eles e capazes de se transformarem em produtos de menor toxidade, devido ao aparato enzimático que possuem. A exposição prolongada a metais impõe uma pressão de seleção que favorece a proliferação de micro-organismos tolerantes/resistentes ao estresse (Hutchinson \& Symington 1997). A capacidade dos micro-organismos converterem substâncias tóxicas em compostos menos nocivos é a base do processo conhecido como biorremediação, que é uma ciência à procura do monitoramento e da aplicação da propriedade de transformação dos micro-organismos na remediação ambiental (Alexander \& Loehr 1992; Borém \& Santos 2001).É uma tecnologia ecologicamente aceitável para o tratamento de áreas contaminadas, que utiliza o estímulo da atividade microbiana para degradar ou converter substâncias (Hurst et al. 2002; Molina-Barahona et al. 2004; Nakagawa \& Andréa 2006).

Este trabalho teve por objetivo avaliar o potencial de biorremediação de bactérias isoladas de ecossistemas praianos da Baía de Guanabara, que possam ser usadas em processos biotecnológicos. transferência de $10 \mathrm{~mL}$ da diluição inicial para $90 \mathrm{~mL}$ de água fosfatada (primeira diluição em série). Desta, transferiu-se $1 \mathrm{~mL}$ para $99 \mathrm{~mL}$ de água fosfatada (segunda diluição em série). Para a água, $10 \mathrm{~mL}$ da amostra foram diluídos diretamente em $90 \mathrm{~mL}$ de água fosfatada (primeira diluição em série) e, desta, mais $10 \mathrm{~mL}$ foram transferidos para $90 \mathrm{~mL}$ de água fosfatada (segunda diluição em série). Todos os procedimentos foram realizados em duplicata, sendo $10 \mathrm{~mL}$ de cada amostra submetidos ao método da membrana filtrante para determinação e isolamento de bactérias como colônias isoladas em membrana de éster de celulose estéreis da Millipore ${ }^{\circledR}$, quadriculada com porosidade e diâmetro de $0,45 \mu \mathrm{m}$ e $47 \mathrm{~mm}$, respectivamente. A membrana contendo os micro-organismos foi colocada sobre meio cromogênico Chromocult ${ }^{\circledR}$ da Merck (Rego 2010). Posteriormente, a placa foi incubada a $37^{\circ} \mathrm{C}$, durante 24 horas. Três a cinco colônias crescidas por placa foram isoladas e armazenadas em meio Luria Bertani (LB) com glicerol a 40\% (Sotero-Martins et al. 2008).

A concentração mínima inibitória (CMI), para avaliar resistência e sensibilidade aos metais, foi realizada de acordo com a metodologia descrita por Cursino et al. (1999), que consistiu na transferência de $50 \mu \mathrm{L}$ da cultura do isolado bacteriano para $3 \mathrm{~mL}$ do meio de LB (Triptona $1 \%, \mathrm{NaCl} 1 \%$ e extrato de levedura $0,5 \%$ ). Os tubos foram incubados a $37^{\circ} \mathrm{C}$, por 24 horas. $\mathrm{O}$ crescimento bacteriano 
foi acompanhado por leitura da densidade óptica (DO) a $600 \mathrm{~nm}$. A cultura de células foi diluída em meio de cultura, em microplaca de cultivo de 96 poços, de modo a ter 0,6 de DO de células. O inóculo da cultura de células em meio sólido foi produzido com o auxílio de um replicador, em placas contendo meio LB com diferentes concentrações dos metais, sendo as mais utilizadas para determinar CMI: 0,5 ; 1,$0 ; 1,5 ; 2,0 ; 2,5 ; 3,0 ; 3,5 ; 4,0 ; 4,5 ; 5,0 ; 5,5 ; 6,0 ; 6,5 ; 7,0 \mathrm{e}$ $7,5 \mathrm{mg}$ de mercúrio/ $\mathrm{L}\left(\mathrm{Hg}\left(\mathrm{NO}_{3}\right)_{2}\right)$ e 0,$0625 ; 0,125 ; 0,25 ; 0,5$; 1,$0 ; 1,5 ; 2,0 ; 2,5$ e $3,0 \mu \mathrm{g}$ de cromo/L $\left(\mathrm{K}_{2} \mathrm{CrO}_{4}\right)$. As placas foram incubadas a $37^{\circ} \mathrm{C}$ em estufa bacteriológica, sendo que o crescimento bacteriano e o perfil de resistência/sensibilidade foram acompanhados durante 24, 48 e 72 horas.

Para investigar a presença dos genes relacionados à degradação do metal $\mathrm{Cr}$, foram desenhados iniciadores, baseado no trabalho de Branco et al. (2008), sendo considerado o número de acesso no GeneBank para as sequências dos genes Chr A e Chr B, da bactéria Ochrobactrumtritici, EF469735. Utilizou-se o programa BLASTn para os alinhamentos das sequências depositadas em tal banco de dados até o dia 1 de junho de 2010. Com a sequência encontrada, foram realizadas as seguintes etapas no BLAST: transferência da sequência escolhida para o BLAST; definição da opção somente para bactérias; busca de similaridade e alinhamento entre as sequências. Gerou-se um quadro de alinhamento de sequências, no qual foram identificados, por aproximação visual, dois trechos com alta similaridade, escore maior ou igual a 200 (Figura 1). As regiões escolhidas foram utilizadas como referência inicial do local em que foi projetado o desenho dos iniciadores, sendo utilizado o programa de desenho de iniciadores em www.stanford.edu/Saccharomyces, com os seguintes parâmetros: $\operatorname{Tm} 50$ e $60^{\circ} \mathrm{C}$, quantidade ótima de CG $40 \%$ e tamanho dos iniciadores entre 18 e 25 nucleotídeos.

O iniciador F1 ChrA se hibridiza com a fita Crick $\left(3^{\prime}-5^{\prime}\right)$ na posição 67 a 87 nt do gene $C h r A$, enquanto o F2 ChrA se hibridiza com a Watson (5'-3') em 297 a 317 nt. A sequência deles foi: Forward primer (F1 ChrA) - 5' TCGCTTGAAGCGGAACAA 3' e Reverse primer (F2 ChrA) - 5' TGGTTCACTTTCCTGCCGT 3'. Para $C h r B$, o iniciador se hibridiza com a fita Crick (3’-5'), na posição 376 a 393 nt do gene $C h r B$, enquanto o F2 ChrB o faz com a Watson (5'-3'), em 569 a 589 nt. A sequência dos iniciadores foi: Forward primer (F1ChrB) - 5' AGCCGATCAACCCAAGGA 3' e Reverse primer (F2 ChrB) -5'AGGTGCGTAAGCTTCGCAAAT 3'.

Os iniciadores para identificar a sequência do gene merA foram descritos por Sotero-Martins et al. (2008), sendo esperado amplicon de 431 pares de bases (pb) para os isolados com mecanismo de resistência ao mercúrio $(\mathrm{Hg})$ via operon merR, sendo eles: Forward primer (F1 merA) - 5' TCGTGATGTTCGACCGCT 3' e Reverse primer (F2merA) -5' TACTCCCGCCGTTTCCAAT 3'.

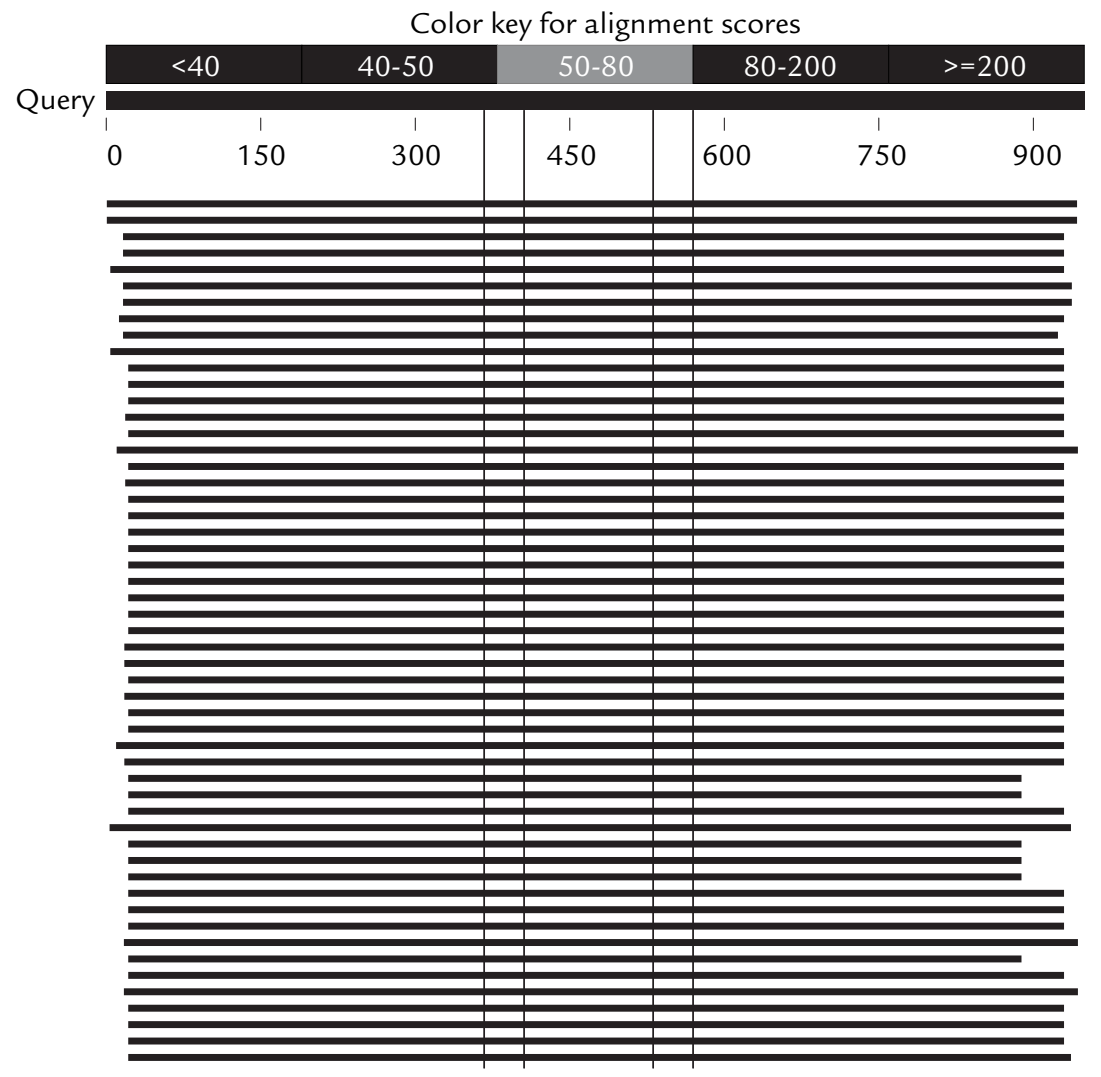

Figura 1

Quadro demonstrativo do alinhamento das sequências no BLAST para o gene ChrB. Fonte: GeneBank. 
Para extração de DNA genômico, utilizou-se a metodologia de lise celular por choque térmico (Nogueira et al. 2004). A extração de DNA plasmidial foi feita por lise alcalina (minipreparação plasmidial), conforme descrito por Sambrook et al. (1989). A reação de amplificação foi gerada no volume de $50 \mu \mathrm{L}$, utilizado gradiente termal cycler. A reação de mistura para a PCR continha $1 \mathrm{U} / \mu \mathrm{L}$ de Taq Polimerase (Invitrogen), tampão de enzima $1 \mathrm{X} ; 0,2 \mathrm{mM}$ de cada dNTPs; $1,25 \mathrm{mM}$ de $\mathrm{MgCl}_{2} ; 0,5 \mu \mathrm{M}$ de cada iniciador e 50 ng de DNA alvo.

\section{RESULTADOS E DISCUSSÃO}

Dos 169 isolados bacterianos selecionados para avaliar o potencial em processos de biorremediação de áreas degradadas, $93 \%$ resultaram positivos para aspecto de interesse
Os ciclos de temperaturas escolhidos para as etapas de desnaturação e extensão foram 94 e $72^{\circ} \mathrm{C}$, respectivamente. A temperatura de anelamento foi específica para cada sistema de iniciadores utilizados, $55^{\circ} \mathrm{C}$ para merA, $56^{\circ} \mathrm{C}$ para $\mathrm{CrhA}$ e $59^{\circ} \mathrm{C}$ para $\mathrm{ChrB}$. Os fragmentos amplificados (amplicons) foram separados por eletroforese em gel de agarose $1 \%$, em 90 volts, por 30 minutos. Os produtos de PCR foram corados com brometo de etídio a $0,5 \mu \mathrm{g} / \mathrm{mL}$ e visualizados em transiluminador sob luz ultravioleta a $365 \mathrm{~nm}$.

\subsection{Resistência e sensibilidade aos metais: mercúrio e cromo}

Do total de isolados selecionados, $48 \%$ (81) foram provenientes da matriz ambiental da água de praia da Baía da Guanabara, contudo apenas $8(10 \%)$ apresentaram resistência a $\mathrm{Hg}$ e a $\mathrm{Cr}$, simultaneamente, na maior concentração, determinada como CIM para $\mathrm{Hg}(7 \mathrm{mg} / \mathrm{L})$ e para $\operatorname{Cr}(2,5 \mu \mathrm{g} / \mathrm{L})$. Doze isolados $(15 \%)$ apresentaram resistência unicamente a $\mathrm{Hg}$ na concentração de maior CIM, e 31 isolados bacterianos (38\%) tiveram apenas para o Cr, na maior concentração de CIM $(2,5 \mu \mathrm{g} / \mathrm{L})$. Da matriz ambiental areia, foram testadas 88 bactérias isoladas $(52 \%)$, sendo que apenas $3(3 \%)$ apresentaram resistência na maior concentração testada para $\mathrm{Hg}$ e 12 $(14 \%)$ com resistência na maior concentração de CIM para Cr. Portanto, o grupo de bactérias isolado da água da Baía de Guanabara foi o que apresentou o maior número de isolados com alta resistência a $\mathrm{Hg}$ e $\mathrm{Cr}$, corroborando com dados que demonstram haver uma relação direta entre o descarte de poluentes e a ocorrência de micro-organismos resistentes (Vahid-Dastgerdi et al. 2006; Kermanshahi et al. 2007).

\subsubsection{Resistência e sensibilidade aos metais: mercúrio e cromo}

Do total de isolados bacterianos testados, 15 resistiram à maior concentração testada $(7 \mathrm{mg} \mathrm{Hg} / \mathrm{L})$, na avaliação de sensibilidade e resistência ao $\mathrm{Hg}$ (Figura 2). No trabalho de Jesus (2007), no qual foram avaliados também isolados de bactérias provenientes das águas dos rios da região do Amazonas, quanto à resistência ao mercúrio, a CIM para 9 isolados foi de 3,5 mg Hg/L. Neste trabalho, os isolados apresentaram maiores níveis de CIM, sendo 12 isolados provenientes de água e 3, de areia.
Figura 2

Frequência de isolados resistentes nas diferentes concentrações de $\mathrm{Hg}$ testadas em $\mathrm{mg} / \mathrm{L}$.

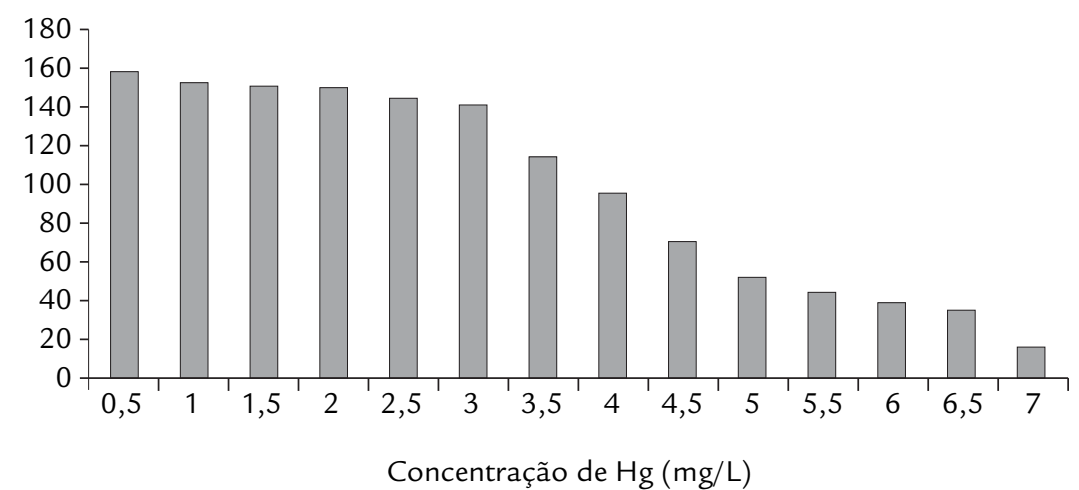




\subsubsection{Resistência específica ao cromo}

A concentração máxima de cromo, em que 45 isolados testados cresceram, foi de 2,5 $\mu \mathrm{g} \mathrm{Cr} / \mathrm{L}$ (Figura 3). Esses resultados sugerem que, dentre os níveis testados, esta é a CIM para tal grupo. Segundo Camargo et al. (2003) e Dermou et al. (2005), o mecanismo de redução enzimática do Cr (VI)

\subsubsection{Presença dos genes: merA, ChrA e ChrB}

Os isolados resistentes a $7 \mathrm{mg} / \mathrm{L}$ de $\mathrm{Hg}$, mais aqueles 18 resistentes a $6,5 \mathrm{mg} / \mathrm{L}$ de $\mathrm{Hg}$ e 7 isolados a $6,0 \mathrm{mg} / \mathrm{mL}$ de $\mathrm{Hg}$ foram selecionados para análise da presença do gene merA, tanto no material genômico quanto no plasmidial.

O tamanho dos amplicons produzidos na reação de PCR, do material dos isolados que apresentaram amplificação positiva para mer $A$, foi de $431 \mathrm{pb}$, em duas amostras de material genômico: 1661 e 1786 da coleção de bactéria do Departamento de Saneamento e Saúde Ambiental da Escola Nacional de Saúde Pública (DSSA/ENSP), como a Cr (III) observado em bactérias está associado à presença da enzima cromato redutase. A baixa resistência ao cromo pelos micro-organismos testados pode ocorrer devido à ausência ou baixa expressão deste aparato enzimático ou de outros mecanismos ainda não descritos.

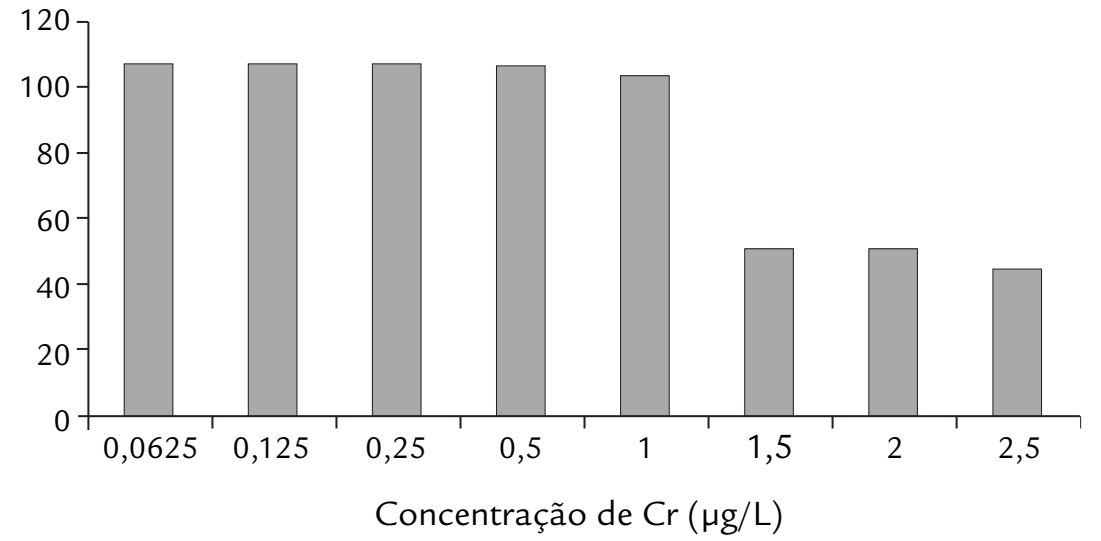

Figura 3

Frequência de isolados resistentes nas diferentes concentrações de $\mathrm{Cr}$ testadas em $\mu \mathrm{g} / \mathrm{L}$.

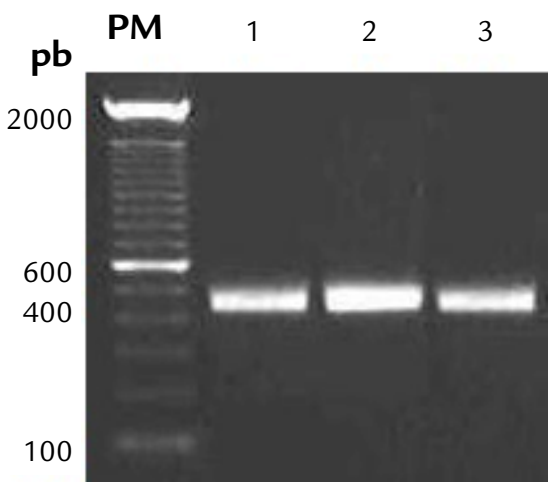

Figura 4

Gel de eletroforese (1,0\% de agarose corado com brometo de etídio $(0,5 \mathrm{~g} / \mu \mathrm{L})$, fotografado sobre luz ultravioleta, contendo amplicons de $431 \mathrm{pb}$, identificando presença do gene merA. Linha 1 - Padrão de peso molecular (PM); linha 2 - controle positivo [E.coli (CPqLMD - cepa 105)]; linha 3 - isolado 1786 (DSSA/ENSP); poço 4 - isolado 1661 (DSSA/ENSP). 


\section{CONCLUSÕES}

Dentre os isolados de bactérias da Baía da Guanabara, foram encontrados micro-organismos com potencial para uso em processos biotecnológicos de biorremediação dos metais estudados, dois deles com mecanismos relacionados com o operon $m e r R$, pois apresentaram o gene merA, que codifica a enzima mercúrio redutase. A maior ocorrência de isolados bacterianos resistentes a altas concentrações de metais foi proveniente da matriz água, corroborando com dados de Jesus (2007). Isso indica provável impacto de contaminantes por efluentes lançados constantemente na água, mantendo o estresse na microbiota.

\section{AGRADECIMENTOS}

Os autores agradecem ao apoio financeiro dado para realização deste trabalho pelo Conselho Nacional de Desenvolvimento Científico e Tecnológico (CNPq),
Concluiu-se ainda que a maioria dos isolados da Baía de Guanabara apresenta padrão de resistência até a faixa de $3 \mathrm{mg}$ de $\mathrm{Hg} / \mathrm{L}$ e de $1 \mu \mathrm{g}$ de $\mathrm{Cr} / \mathrm{L}$, sendo que $15 \%$ dos isolados testados apresentaram resistência a $\mathrm{Hg}$ na concentração de $7 \mathrm{mg} \mathrm{Hg} / \mathrm{L}$, e dois que possuem o gene mer $\mathrm{A}$ foram resistentes até esta faixa de concentração. Contudo, há outros mecanismos relacionados à resistência ao $\mathrm{Hg}$ que se diferem do operon merR. Todavia, nos $38 \%$ de isolados que apresentaram resistência até a concentração $\mathrm{Cr}$ de 2,5 $\mu \mathrm{g} / \mathrm{L}$, não foram detectados os genes $\mathrm{ChrA}$ e $\mathrm{ChrB}$ nas condições utilizadas.
Edital MCT/CNPq/CT-Agro/CT-Hidro/MAPA-SDC-SPAE 44/2008 - Recuperação de Áreas Degradadas, processo 577.432/2008-7.

\section{REFERÊNCIAS}

Alexander M. \& Loehr R.C. 1992. Bioremediation Review. Science, 258:874.

Baruthio F. 1992. Toxic effects of chromium and its compounds. Review. Biological Trace Element Research, 32:145-153.

Borém A. \& Santos F.R. 2001. Biotecnologia Simplificada. Editora Suprema, Visconde do Rio Branco, Minas Gerais, 250 p.

Branco R., Chung A.P., Johnston T., Gurel V., Morais P. \& Zhitkovich A. 2008. The chromate-inducible chrBACF operon from the transposable element TnOtChr confers resistance to chromium (VI) and superoxide. Journal of Bacteriology, 190:6996-7003.

Camargo F.A., Bento F.M., Okeke B.C. \& Frankenberger W.T. 2003. Chromate reduction by chromium-resistant bacteria isolated from soils contaminated with dichromate. Journal of Environmental Quality, 32:1228-1233.

Cervantes C. 2001. Interactions of chromium with microorganisms and plants. Microbiological Reviews, 25:335-347.

Cursino L., Oberda S.M., Cecilio R.V., Moreira R.M., Chartone-Souza E. $\&$ Nascimento A.M.A. 1999. Mercury concentration in the sediment at different gold prospecting sites along the Carmo stream, Minas Gerais, Brazil, and frequency of resistant bacteria in the respective aquatic communities. Hydrobiologia, 394:5-12.

Deng X., Zheng Y. \& Li Q. 2006. Effect of ambient conditions on simultaneous growth and bioaccumulation of mercuric ion by genetically engineered E. coli JM109. Journal of Hazardous Materials, 136:233-238.

Dermou E., Velissariou A., Xenos D. \& Vayenas D.V. 2005. Biological chromium (VI) reduction using a trickling filter. Journal of Hazardous Materials, 126:78-85.

Hines M.E., Faganeli J., Adatto I.A., Horvat I. 2006. Microbial mercury transformation in marine, esturiane and freshwater sediment downstream of the Idrija mercury mine, Slovenia. Geochemistry, 21:1924-1939.

Hurst C.J., Crawford R.L., Knudsen G.R., McInerney M.J. \& Stetzenbach L.D. (Eds.) 2002. Manual of environmental microbiology. ASM Press, Washington D.C., 1094 p.

Hutchinson T.C. \& Symington M.S. 1997. Persistence of metal stress in a forested ecosystem near Sudbury, 66 years after closure of the O'Donnell roast bed. Journal of Geochemical Exploration, 58:323-330. 
Jesus M.S. 2007. Identificação e caracterização de bactérias resistentes ao mercúrio em sistemas aquáticos da região Amazônica: uma nova proposta de biorremediação. Dissertação de Mestrado, Programa Multi-institucional em Biotecnologia, Universidade Federal do Amazonas, 98 p.

Kermanshahi R.S., Ghazifard A. \& Tavakoli A. 2007. Identification of bacteria resistant to heavy metals in the soils of Isfahan Province. Iranian Journal of Science and Technology, A1:7-16.

Lima E. \& Legey L.F.L. 2010. Water Quality Restoration in Rio de Janeiro: From a Piecemeal to a Systems Approach. Journal of Environment \& Development, 19:375-396.

Molina-Barahona L., Rodríguez-Vázquez R., Hernández-Velasco M., Vega-Jarquín C., Zapata-Pérez O., Mendoza-Cantú A. \& Albores, A. 2004. Diesel removal from contaminated soils by biostimulation and supplementation with crop residues. Applied Soil Ecology, 27:165-175.

Nakagawa A.R. \& Andréa M.M. 2006. Efeito de alterações nas características do solo sobre a degradação de hexaclorobenzeno. Revista Brasileira de Ciência do Solo, 30:575-582.

Nogueira C.A.M., Momesso C.A.S., Machado R.L.D.,Almeida M.T.G. \& Rossit A.R.B. 2004. Desempenho de kits comerciais e protocolos laboratoriais para a extração de DNA genômico bacteriano. Revista Panamericana de Infectologia, 6:35-38.

Pereira R.S. 2004. Identificação e caracterização das fontes de poluição em sistemas hídricos. Revista Eletrônica de Recursos Hídricos. IPH-UFRGS. 1:20-36.

Rego J.C.V. 2010. Qualidade sanitária de água e areia de praias da Baía de Guanabara. Dissertação de Mestrado do Programa de Saúde Pública, Escola Nacional de Saúde Pública Sergio Arouca, Fundação Oswaldo Cruz, 132 p.

Sambrook J., Fritsch E.F., Maniatis T. \& Cold Spring Harbor Laboratory. 1989. Molecular Cloning - A laboratory Manual. Cold Spring Harbor Laboratory Press, Cold Spring Harbor, N.Y, 3v.

Sotero-Martins A., Jesus M.S., Lacerda M., Moreira J.C., Filgueiras A.L.L. \& Barrocas P.R.G. 2008. A conservative region of the mercuric reductase gene $(m e r A)$ as a molecular marker of bacterial mercury resistance. Brazilian Journal of Microbiology, 39:307-310.

Vahid-Dastgerdi M., Shanbehzadeh S. \& Zahabzadeh A. 2006. Investigation of heavy metal concentration in water, soil and plant in GavkhoniTalab and their ecologic effects. Quarterly Hygiene and Health, 1:1-6. 